\title{
Low-temperature crystallization of tantalum pentoxide films under elevated pressure
}

\author{
Chung-Hsin Lu*, Chung-Han $\mathrm{Wu}$ \\ Electronic and Electro-optical Ceramics Laboratory, Department of Chemical Engineering, \\ National Taiwan University, Taipei, Taiwan ROC
}

Received 27 February 2005; received in revised form 28 June 2005; accepted 3 July 2005

Available online 1 September 2005

\begin{abstract}
$\mathrm{Ta}_{2} \mathrm{O}_{5}$ thin films deposited via a metal-organic decomposition method were crystallized via atmospheric pressure annealing and a high-pressure crystallization (HPC) process. $\mathrm{Ta}_{2} \mathrm{O}_{5}$ thin films started to become crystallized at $700{ }^{\circ} \mathrm{C}$ as subjected to atmospheric pressure annealing. When the HPC process was adopted and annealing at $16.5 \mathrm{MPa}$ was performed, the crystallization temperature of $\mathrm{Ta}_{2} \mathrm{O}_{5}$ films was greatly dropped to as low as $350^{\circ} \mathrm{C}$. The developed HPC process considerably reduced the thermal budget and energy consumption during film processing. The crystallized $\mathrm{Ta}_{2} \mathrm{O}_{5}$ phase was found to be homogeneously distributed within the HPC-derived films. With annealing at $700{ }^{\circ} \mathrm{C}$ under atmospheric pressure, the silicon species diffused from the substrates into the $\mathrm{Ta}_{2} \mathrm{O}_{5}$ layers, thereby leading to reduced dielectric constants. The HPC process effectively suppressed the interdiffusion between the substrates and dielectric layers by lowering the required heating temperature, and also significantly increased the dielectric constants of $\mathrm{Ta}_{2} \mathrm{O}_{5}$ thin films. The HPC process was confirmed to effectively lower the crystallization temperature and improve the dielectric properties of $\mathrm{Ta}_{2} \mathrm{O}_{5}$ thin films.
\end{abstract}

(c) 2005 Elsevier Ltd. All rights reserved.

Keywords: $\mathrm{Ta}_{2} \mathrm{O}_{5} ;$ Films; X-ray methods

\section{Introduction}

Recently there is a rising demand for improving the performance of dynamic random access memory (DRAM). This kind of improvement can be achieved by increasing the number of interconnected layers in integrated circuits. In light of the trend for making compact devices, the development of new materials having high dielectric constants becomes much more important. ${ }^{1}$ Tantalum pentoxide $\left(\mathrm{Ta}_{2} \mathrm{O}_{5}\right)$ has been demonstrated to be a promising dielectric material used in dynamic random access memories. ${ }^{2} \mathrm{Ta}_{2} \mathrm{O}_{5}$ films have been utilized as capacitors, ${ }^{3}$ oxygen sensors, ${ }^{4}$ and optical wave guides. ${ }^{5,6}$ These applications are based on the good chemical stability, high dielectric constants, high ionic conductivity, and superior optical properties of $\mathrm{Ta}_{2} \mathrm{O}_{5}$ films.

\footnotetext{
* Corresponding author.

E-mail address: chlu@ccms.ntu.edu.tw (C.-H. Lu).
}

$\mathrm{Ta}_{2} \mathrm{O}_{5}$ thin films have been deposited by various techniques, such as chemical vapor deposition, thermal oxidation, ${ }^{7-9}$ sputtering, ${ }^{10}$ and chemical solution deposition. ${ }^{11}$ The crystallization temperature of $\mathrm{Ta}_{2} \mathrm{O}_{5}$ films was reported to be around $700^{\circ} \mathrm{C} .{ }^{12}$ The high-temperature heating results in interdiffusion of species between dielectric layers and substrates, and the diffusion of silicon leads to a reduction in the effective dielectric constants. In order to suppress the interfacial reactions between dielectric layers and microelectronic devices, the development of novel low-temperature crystallization processes is necessary.

A new high-pressure crystallization (HPC) process was lately developed by our group to reduce the crystallization temperature of $\mathrm{Pb}(\mathrm{Zr}$, Ti $) \mathrm{O}_{3}$ films to $350{ }^{\circ} \mathrm{C}$. ${ }^{13,14}$ For conventional hydrothermal methods, the solution containing the constituent ions is filled into an autoclave container, and the crystallized particles will be formed due to the nucleation and growth in high-pressure environment. On the other hand, in the HPC process, only distilled water is filled in the autoclave 
container and the amorphous precursor films are positioned above the water surface. The amorphous films become crystallized during the heating processes in a high vapor-pressure environment at elevated temperatures.

In this study, we applied a similar process to crystallize tantalum oxide thin films at low temperatures. The precursor films of tantalum oxide were deposited via a metalorganic deposition (MOD) method. The deposited films were annealed via two processes viz. atmospheric pressure annealing and the HPC process. The microstructural and phase evolutions during these two processes were investigated. In addition, the diffusion phenomenon and the dielectric properties of $\mathrm{Ta}_{2} \mathrm{O}_{5}$ thin films crystallized via both processes were also studied. The HPC process was confirmed to effectively lower the crystallization temperature and improve the dielectric properties of $\mathrm{Ta}_{2} \mathrm{O}_{5}$ thin films.

\section{Experimental}

$\mathrm{Ta}_{2} \mathrm{O}_{5}$ thin films were prepared via a metal-organic decomposition method. Tantalum ethoxide $\left[\mathrm{Ta}\left(\mathrm{OC}_{2} \mathrm{H}_{5}\right)_{5}\right]$ dissolved in toluene was used as the starting materials. The prepared precursors were spin-coated onto $\mathrm{Pt} / \mathrm{Ti} / \mathrm{SiO}_{2} / \mathrm{Si}$ substrates at a spinning rate of 3000-4000 rpm. Silicon wafers were first thermally oxidized to form a $\mathrm{SiO}_{2}$ layer with a thickness of $200 \mathrm{~nm}$. Then titanium was deposited on the top of this $\mathrm{SiO}_{2}$ layer via the electron-gun technique to form a $30 \mathrm{~nm}$ thick layer. Platinum was subsequently deposited on the top of the titanium layer via the same technique to form a $200 \mathrm{~nm}$ thick layer. The platinum layer was used as the bottom electrode, and the titanium layer served to enhance the adhesion of the platinum layer onto the silicon oxide layer. The coated films were baked on a hot plate at $150{ }^{\circ} \mathrm{C}$ for $30 \mathrm{~min}$ to evaporate the organic solvent, and subsequently pyrolyzed at $350^{\circ} \mathrm{C}$ for $30 \mathrm{~min}$. The spinning-baking-pyrolyzing cycle was repeated for three to four times to achieve proper film thickness. The $350^{\circ} \mathrm{C}$ pyrolyzed films were amorphous with a thickness of around $0.20 \mu \mathrm{m}$.

The pyrolyzed films were annealed via two types of annealing processes. The first method was to anneal the pyrolyzed films in a furnace under atmospheric pressure $(0.1 \mathrm{MPa})$ in flowing oxygen at temperatures ranging from 500 to $800^{\circ} \mathrm{C}$ at a heating rate of $30^{\circ} \mathrm{C} / \mathrm{s}$. The second method (the HPC process) was to anneal the precursor films in a closed bomb under high pressure. A sealed stainless-steel (T316-SS) bomb was used as the autoclave container. The bottom of the bomb was filled with distilled water to produce a high vapor-pressure environment at elevated temperatures. The pyrolyzed films were positioned above the water surface and the pressure in the bomb was determined by the saturated vapor-pressure. This autoclave container was surrounded by a heating system which was controlled by a programmable controller. One thermal couple was inserted into the water for measuring the temperature. The heating rate was set to $10^{\circ} \mathrm{C} / \mathrm{min}$. Once it reached the pre-set temperature in the autoclave, the heating process was continued for $30 \mathrm{~min}$ to $1 \mathrm{~h}$. Being sealed in a closed bomb at elevated temperature, the saturated vapor created a high-pressure environment during the heating process. When the temperature was raised to $250-350{ }^{\circ} \mathrm{C}$, the pressure was increased to $4.0-16.5 \mathrm{MPa}$.

The formed crystalline phases of the heated films were identified via X-ray diffraction (XRD) analysis. The surface morphologies were examined via scanning electron microscopy (SEM) and also via an atomic force microscope (AFM) using a tapping mode with amplitude modulation. Secondary ion mass spectroscopy (SIMS) was conducted to determine the depth profiles of the prepared thin films. In order to analyze the distribution of phases in the crystallized thin films, grazing incident X-ray diffraction (GIXRD) was performed. The dielectric properties of tantalum oxide films were measured using an impedance analyzer. The measuring voltage was $0.1 \mathrm{~V}$ and the frequency was between $50 \mathrm{~Hz}$ and $1 \mathrm{MHz}$.

\section{Results and discussion}

\subsection{Crystallization of $\mathrm{Ta}_{2} \mathrm{O}_{5}$ thin films annealed under atmospheric pressure}

The as-deposited films pyrolyzed at $350{ }^{\circ} \mathrm{C}$ were found to be amorphous according to XRD analysis. Post-annealing was required to crystallize $\mathrm{Ta}_{2} \mathrm{O}_{5}$ thin films. Fig. 1 illustrates the XRD patterns of $\mathrm{Ta}_{2} \mathrm{O}_{5}$ thin films annealed under atmospheric pressure at various temperatures. When the annealing temperature was increased up to $650^{\circ} \mathrm{C}$, the heated films remained amorphous. With $700^{\circ} \mathrm{C}$ annealing, the crystallization process began to proceed, and $\beta-\mathrm{Ta}_{2} \mathrm{O}_{5}$ was formed. The XRD pattern of this formed phase was consistent with the data recorded in ICDD No. $25-922 .{ }^{15}$ With a further rise in the annealing temperature, the crystallinity of $\beta-\mathrm{Ta}_{2} \mathrm{O}_{5}$ was

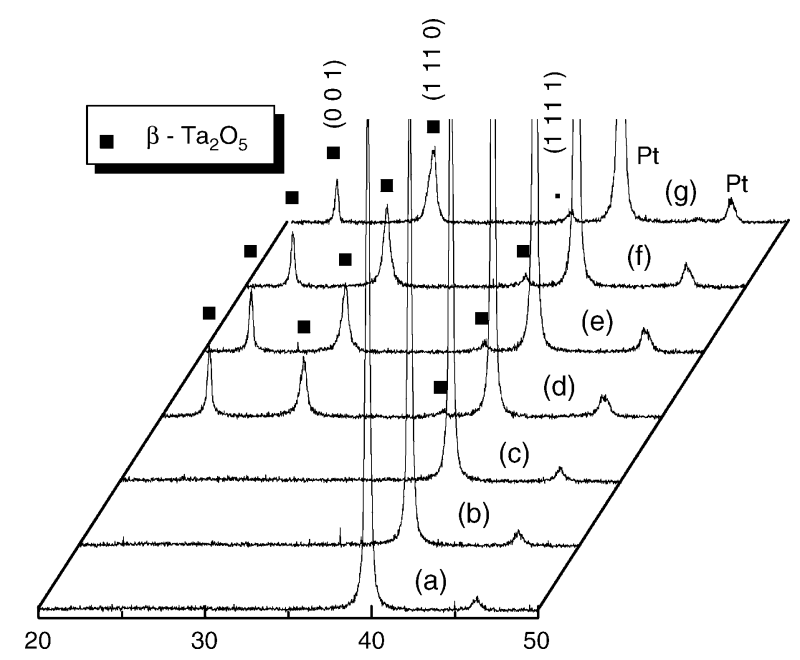

Fig. 1. X-ray diffraction patterns of (a) as-pyrolyzed $\mathrm{Ta}_{2} \mathrm{O}_{5}$ thin films and the films annealed under atmospheric pressure at (b) $600^{\circ} \mathrm{C}$, (c) $650^{\circ} \mathrm{C}$, (d) $700^{\circ} \mathrm{C}$, (e) $750^{\circ} \mathrm{C}$, (f) $800^{\circ} \mathrm{C}$, and (g) $850^{\circ} \mathrm{C}$. 


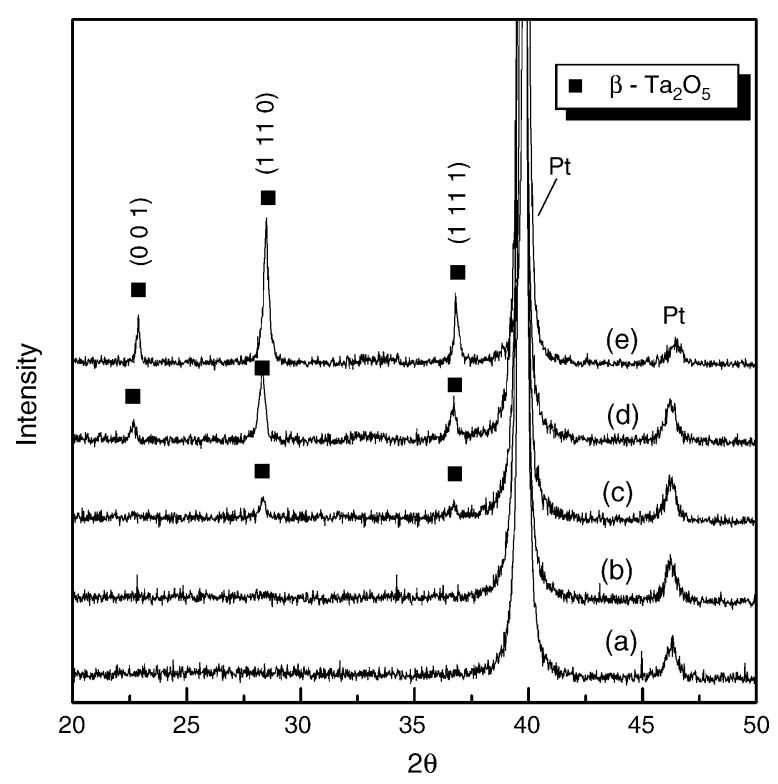

Fig. 2. X-ray diffraction patterns of (a) as-pyrolyzed $\mathrm{Ta}_{2} \mathrm{O}_{5}$ thin films and the HPC-derived $\mathrm{Ta}_{2} \mathrm{O}_{5}$ films annealed at (b) $300^{\circ} \mathrm{C}$ under $8.6 \mathrm{MPa}$, (c) $320^{\circ} \mathrm{C}$ under $11.3 \mathrm{MPa}$, (d) $340^{\circ} \mathrm{C}$ under $14.5 \mathrm{MPa}$, and (e) $350{ }^{\circ} \mathrm{C}$ under $16.5 \mathrm{MPa}$

enhanced. These results indicate that the crystallization temperature of $\mathrm{Ta}_{2} \mathrm{O}_{5}$ thin films needs to be as high as $700^{\circ} \mathrm{C}$, which is similar to that reported in literature. ${ }^{16}$

\subsection{Crystallization of $\mathrm{Ta}_{2} \mathrm{O}_{5}$ thin films via the $\mathrm{HPC}$ process}

In order to lower the crystallization temperature of $\mathrm{Ta}_{2} \mathrm{O}_{5}$ thin films, the high-pressure crystallization process was adopted. The XRD patterns of $\mathrm{Ta}_{2} \mathrm{O}_{5}$ films annealed via the HPC process are illustrated in Fig. 2. No crystallized phase was observed after annealing at $300^{\circ} \mathrm{C}$ under $8.6 \mathrm{MPa}$ for $1 \mathrm{~h}$. As the heating temperature and process pressure increased respectively to $320^{\circ} \mathrm{C}$ and $11.3 \mathrm{MPa}$, a small amount of crystallized $\mathrm{Ta}_{2} \mathrm{O}_{5}$ was formed. Well-crystallized $\mathrm{Ta}_{2} \mathrm{O}_{5}$ thin films were obtained as the heating temperature reached $340^{\circ} \mathrm{C}$ under a process pressure of $14.5 \mathrm{MPa}$. The formed phase was confirmed to be $\beta-\mathrm{Ta}_{2} \mathrm{O}_{5}$. Fully crystallized $\mathrm{Ta}_{2} \mathrm{O}_{5}$ thin films were produced after annealing at $350{ }^{\circ} \mathrm{C}$ under 16.5 MPa, and the formed phase was confirmed to be $\beta$ $\mathrm{Ta}_{2} \mathrm{O}_{5}$. The above results indicate that the adoption of the high-pressure process successfully lowered the crystallization temperature of $\mathrm{Ta}_{2} \mathrm{O}_{5}$ thin films from 700 to $350{ }^{\circ} \mathrm{C}$. This temperature was lower than the results reported by Lin et al., ${ }^{17}$ who deposited $\mathrm{Ta}_{2} \mathrm{O}_{5}$ thin films on $\mathrm{Ru}$-film coated substrates and annealed the films in $\mathrm{H}_{2}$ atmosphere to reduce the crystallization temperature of $\mathrm{Ta}_{2} \mathrm{O}_{5}$ thin films to $400{ }^{\circ} \mathrm{C}$. The developed HPC process in this study considerably reduced the thermal budget and energy consumption during film processing.

Fig. 3 shows the SEM micrographs of $\mathrm{Ta}_{2} \mathrm{O}_{5}$ thin films crystallized via the HPC process. After annealing at $300^{\circ} \mathrm{C}$ under 8.6 MPa as shown in Fig. 3(a), the films were amorphous and no specific feature was observed. Once the films began to become crystallized after annealing at $320^{\circ} \mathrm{C}$ under 11.3 $\mathrm{MPa}$, certain special clusters with irregular shapes were formed as demonstrated in Fig. 3(b). These clusters were nuclei of crystallized $\mathrm{Ta}_{2} \mathrm{O}_{5}$. With $340{ }^{\circ} \mathrm{C}$ annealing under 14.5 MPa, the surface of $\mathrm{Ta}_{2} \mathrm{O}_{5}$ thin film was covered with the clustered grains with a size of $0.1-0.2 \mu \mathrm{m}$. When the temperature and pressure were increased respectively to $350{ }^{\circ} \mathrm{C}$ and $16.5 \mathrm{MPa}$, the number of the clustered grains was further increased. By comparing the XRD data in Fig. 2 with the SEM photographs in Fig. 3, the crystallization of $\mathrm{Ta}_{2} \mathrm{O}_{5}$ was confirmed to take place after annealing at $320^{\circ} \mathrm{C}$ under 11.3 MPa.

The surface morphology of $\mathrm{Ta}_{2} \mathrm{O}_{5}$ thin films prepared via the two processes was examined via AFM. Fig. 4(a) shows the AFM image of the $350^{\circ} \mathrm{C}$ pyrolyzed films. The pyrolyzed film was rather smooth without any specific feature. The microstructures of $\mathrm{Ta}_{2} \mathrm{O}_{5}$ prepared via atmospheric pressure annealing at $700^{\circ} \mathrm{C}$ and the HPC process at $350^{\circ} \mathrm{C}$ under 16.5 MPa are shown in Fig. 4(b) and (c), respectively. Both films exhibited a particulate feature. The magnitudes of the roughness of the film prepared via atmospheric pressure annealing and the HPC process were 4.5 and $10.1 \mathrm{~nm}$, respectively. The greater roughness in the films prepared via the HPC process is considered to result from the formation of clustered grains during the crystallization process.

\subsection{Effects of pressure and annealing time on the formation of crystallized $\mathrm{Ta}_{2} \mathrm{O}_{5}$ during the HPC process}

For investigating the influence of pressure on the formation of crystallized $\mathrm{Ta}_{2} \mathrm{O}_{5}$, various pressures were applied during the HPC process. To adjust the pressure during the HPC process, various amounts of distilled water were filled into the bomb. Saturated vapor-pressure was generated when provided with sufficient quantity of water. If the water amount was insufficient, vapor-pressure was reduced. As illustrated in Fig. 5, the films remained amorphous after heating at $340^{\circ} \mathrm{C}$ under $10.3 \mathrm{MPa}$. When the pressure was increased to 11.0 MPa, a small amount of crystallized $\mathrm{Ta}_{2} \mathrm{O}_{5}$ was formed. Once the vapor-pressure was raised to $14.5 \mathrm{MPa}$ and reached the saturated status at $340^{\circ} \mathrm{C}$, well-crystallized $\mathrm{Ta}_{2} \mathrm{O}_{5}$ thin films were formed. These results indicate that the crystallization process is dependent on the pressure during the HPC process.

For elucidating the effects of annealing time on the formation of crystallized $\mathrm{Ta}_{2} \mathrm{O}_{5}$, various heating durations were performed during the HPC process. Fig. 6(a)-(c) illustrate the XRD patterns of $\mathrm{Ta}_{2} \mathrm{O}_{5}$ thin films heated at $350^{\circ} \mathrm{C}$ under 16.5 MPa for 15, 30, and $60 \mathrm{~min}$, respectively. After heating for $15 \mathrm{~min}$, a small amount of crystallized $\mathrm{Ta}_{2} \mathrm{O}_{5}$ was produced. With an increase in the heating time, the crystallization degree of $\mathrm{Ta}_{2} \mathrm{O}_{5}$ thin films was increased. After heating for $60 \mathrm{~min}$, the crystallization of $\mathrm{Ta}_{2} \mathrm{O}_{5}$ thin films was nearly complete. Prolonging the heating time led to complete 

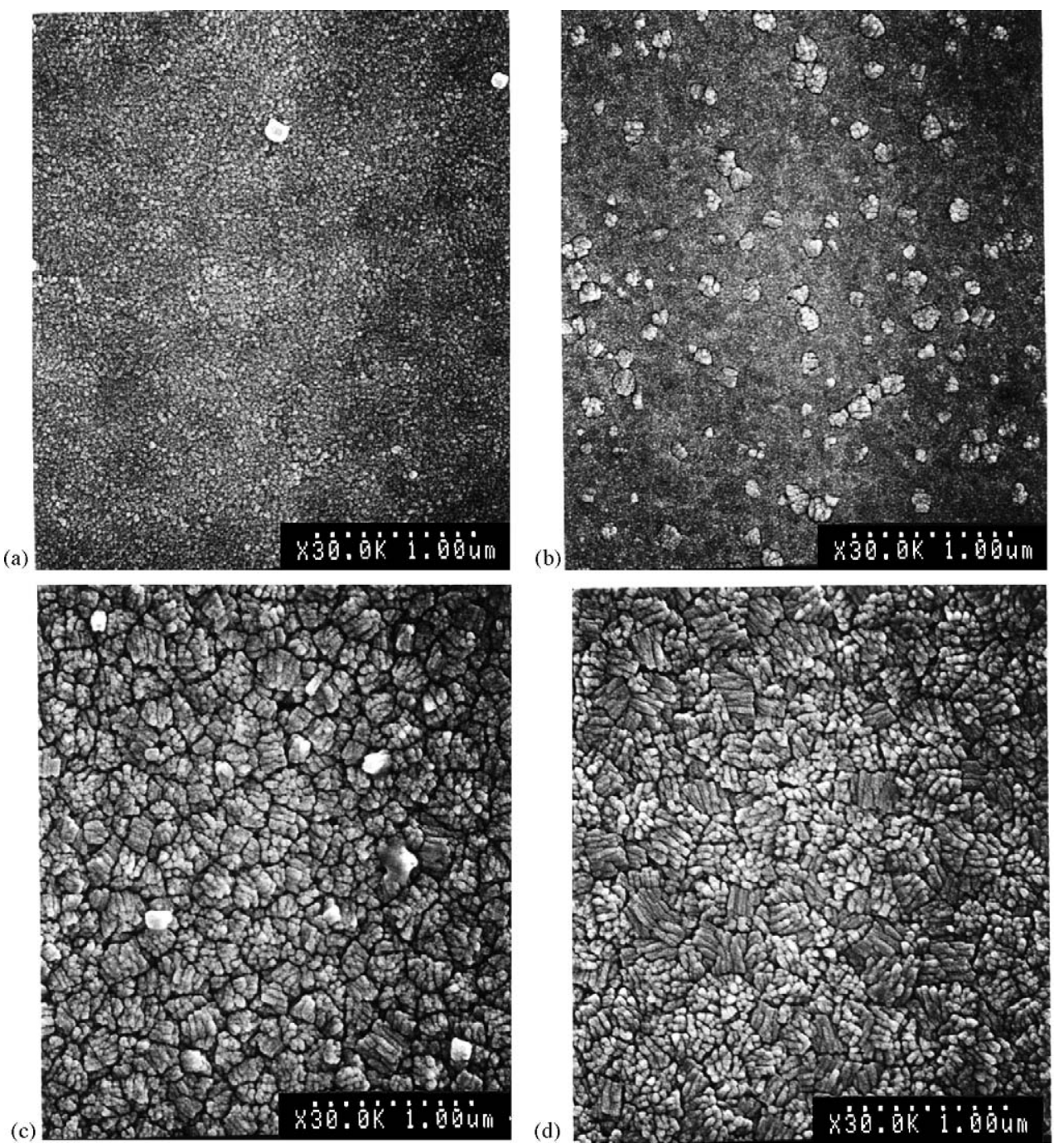

Fig. 3. Scanning electron micrographs of the HPC-derived $\mathrm{Ta}_{2} \mathrm{O}_{5}$ films annealed at (a) $300^{\circ} \mathrm{C}$ under $8.6 \mathrm{MPa}$, (b) $320^{\circ} \mathrm{C}$ under $11.3 \mathrm{MPa}$, (c) $340{ }^{\circ} \mathrm{C}$ under 14.5 MPa, and (d) $350^{\circ} \mathrm{C}$ under $16.5 \mathrm{MPa}$.

development of crystallized $\mathrm{Ta}_{2} \mathrm{O}_{5}$. The formation of crystallized phases from amorphous films usually involves both the nucleation and growth stages. According to the classical nucleation theory, it is known that the critical nucleation energy for forming stable nuclei depends on the pressure. ${ }^{18,19}$ The high-pressure annealing process might lead to a reduction in the critical free energy required for the formation of stable nuclei, and promotes the nucleation process at low temperatures. A possible alternative mechanism is that the high vapor-pressure developed during the process probably forms a water coating on the film surface, thereby facilitating a dissolution-precipitation process to produce the crystallized nuclei at low temperatures. ${ }^{20}$

In order to examine the distribution of crystallized $\mathrm{Ta}_{2} \mathrm{O}_{5}$ within the films, grazing incidence $\mathrm{X}$-ray diffraction analysis was performed. Fig. 7 shows the GIXRD patterns of $\mathrm{Ta}_{2} \mathrm{O}_{5}$ thin films prepared via the two different processes at incidence angles $\alpha=0.5^{\circ}, 1^{\circ}$, and $1.5^{\circ}$. Based on the calculation equation of penetration depth, ${ }^{21}$ the depths that X-ray pene- trated into the thin films were calculated to be $0.07,0.14$, and $0.21 \mu \mathrm{m}$ for the above three incidence angles. As illustrated in Fig. 7(a), the crystallinity of $\mathrm{Ta}_{2} \mathrm{O}_{5}$ thin films annealed at $700^{\circ} \mathrm{C}$ under atmospheric pressure was almost the same in different depths of thin films. From Fig. 7(b) and (c), similar behaviors were also observed in $\mathrm{Ta}_{2} \mathrm{O}_{5}$ thin films prepared via the HPC process. In spite of the difference in crystallization temperature, the crystallinity of $\mathrm{Ta}_{2} \mathrm{O}_{5}$ thin films was independent of the distinct position of depth. The GIXRD results corroborate that crystallized $\mathrm{Ta}_{2} \mathrm{O}_{5}$ phase was homogeneously distributed in the thin films prepared via the both processes.

The depth profiles of constituent species measured via SIMS for $\mathrm{Ta}_{2} \mathrm{O}_{5}$ thin films prepared via both processes are illustrated in Fig. 8. As shown in Fig. 8(a), the distribution of silicon and titanium expended through platinum to $\mathrm{Ta}_{2} \mathrm{O}_{5}$ layer as the thin film was annealed at $700^{\circ} \mathrm{C}$ under atmospheric pressure. The SIMS analysis indicated that the hightemperature annealing inevitably caused extensive outward 


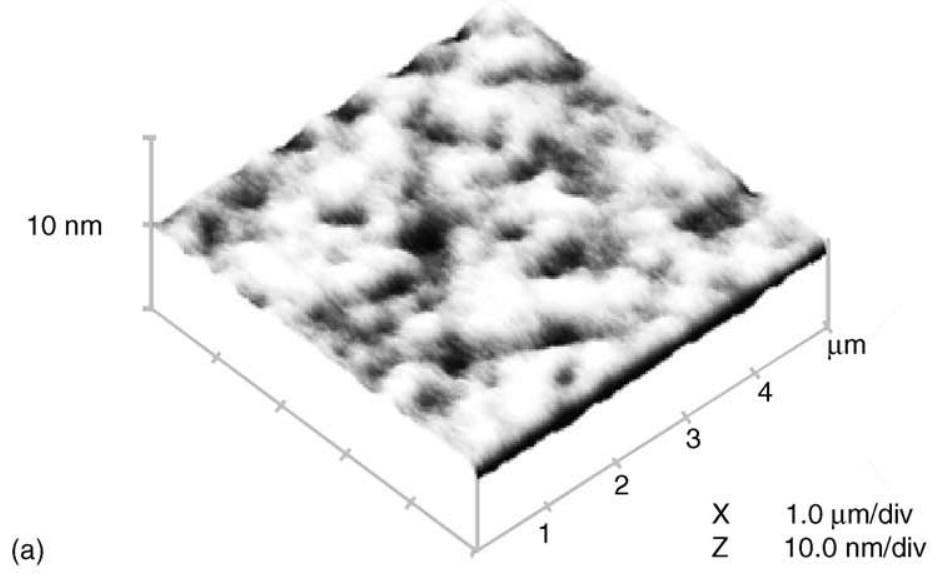

(b)
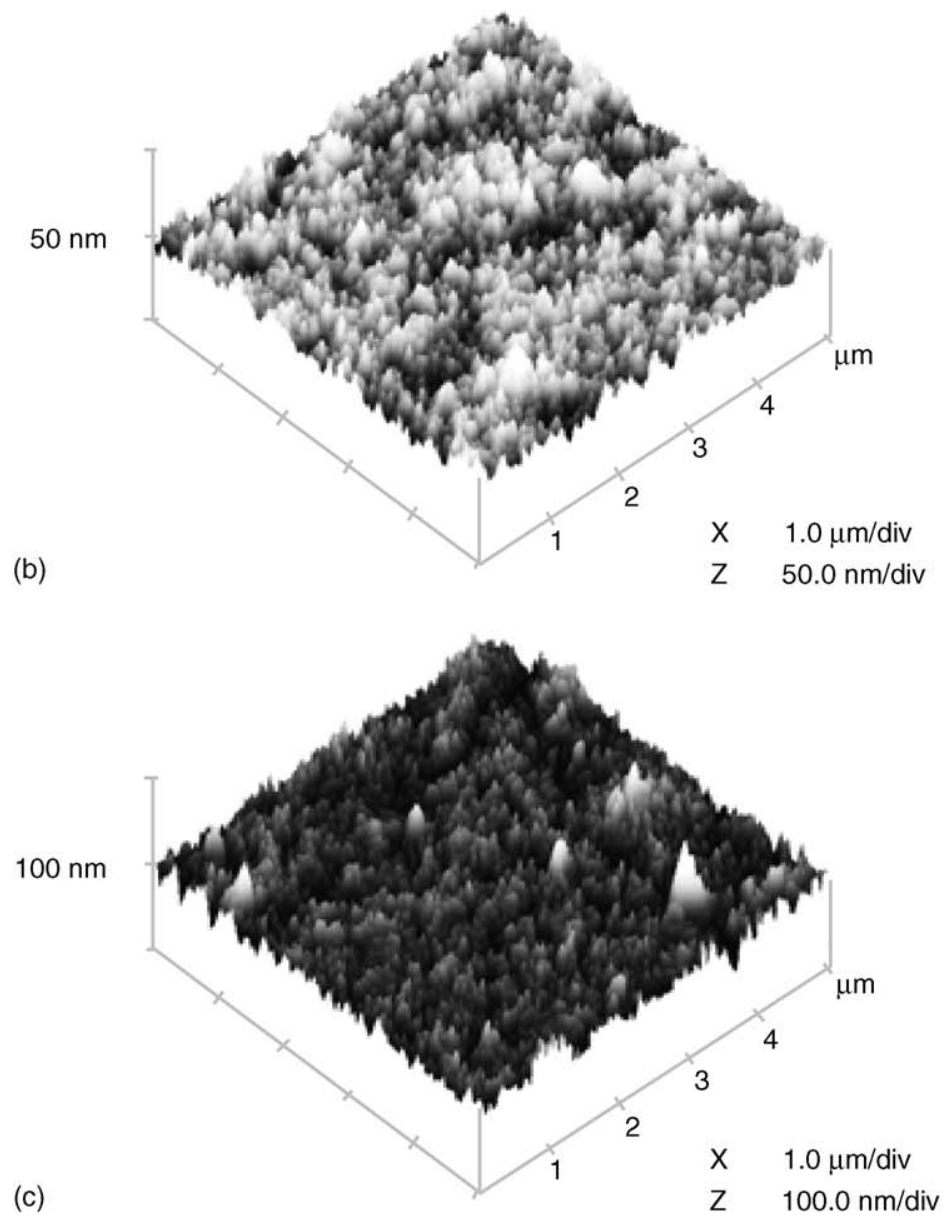

Fig. 4. Atomic force micrographs of (a) as-pyrolyzed $\mathrm{Ta}_{2} \mathrm{O}_{5}$ films, (b) $\mathrm{Ta}_{2} \mathrm{O}_{5}$ films annealed at $700{ }^{\circ} \mathrm{C}$ under atmospheric pressure, and (c) $\mathrm{Ta}_{2} \mathrm{O}_{5}$ films annealed at $350{ }^{\circ} \mathrm{C}$ under $16.5 \mathrm{MPa}$.

diffusion of silicon and titanium species from the substrates and bottom electrodes into the dielectric layers. On the other hand, when the films were annealed via the HPC process at $350^{\circ} \mathrm{C}$ as illustrated in Fig. 8(b), the diffusion of titanium and silicon species was limited. The SIMS results suggest that the interdiffusion between the substrates and dielectric layers was effectively suppressed by employing the HPC process due to lowering of the required crystallization temperatures.
The dielectric properties of $\mathrm{Ta}_{2} \mathrm{O}_{5}$ thin films crystallized via atmospheric pressure annealing and the HPC process were determined. The dielectric constant of $\mathrm{Ta}_{2} \mathrm{O}_{5}$ thin films annealed at $700{ }^{\circ} \mathrm{C}$ under atmospheric pressure was 27.5. After annealing at $850^{\circ} \mathrm{C}$, the constant was reduced to 11 . The decrease in the dielectric constant of $\mathrm{Ta}_{2} \mathrm{O}_{5}$ thin films was considered to relate to the diffusion of silicon species. The diffused silicon species formed $\mathrm{SiO}_{2}$ at the interface 


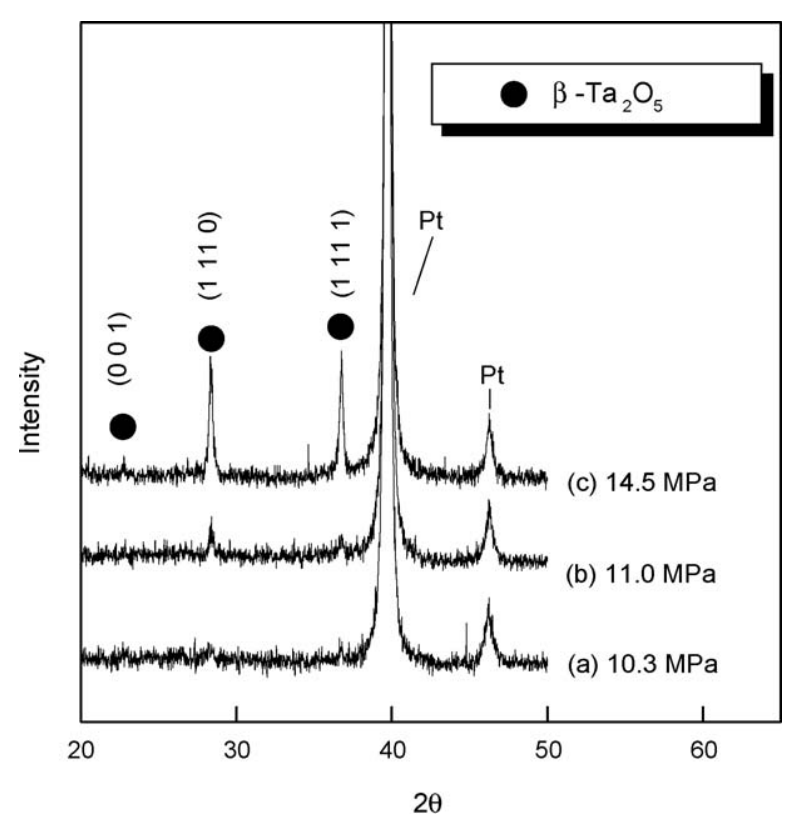

Fig. 5. X-ray diffraction patterns of $\mathrm{Ta}_{2} \mathrm{O}_{5}$ thin films annealed at $340^{\circ} \mathrm{C}$ under (a) $10.3 \mathrm{MPa}$, (b) $11.0 \mathrm{MPa}$, and (c) $14.5 \mathrm{MPa}$.

between $\mathrm{Ta}_{2} \mathrm{O}_{5}$ and Pt layers and resulted in reduced dielectric constant of dielectric layers. ${ }^{22}$ On the other hand, the dielectric constant of $\mathrm{Ta}_{2} \mathrm{O}_{5}$ thin films crystallized at $350{ }^{\circ} \mathrm{C}$ via the HPC process was 30.0. The greater dielectric constant of $\mathrm{Ta}_{2} \mathrm{O}_{5}$ thin films crystallized via the HPC process was ascribed to the low crystallization temperature that effectively suppressed the diffusion of silicon species. The HPC process was confirmed to not only lower the crystallization temperature of $\mathrm{Ta}_{2} \mathrm{O}_{5}$ thin films, but also improve their dielectric properties.

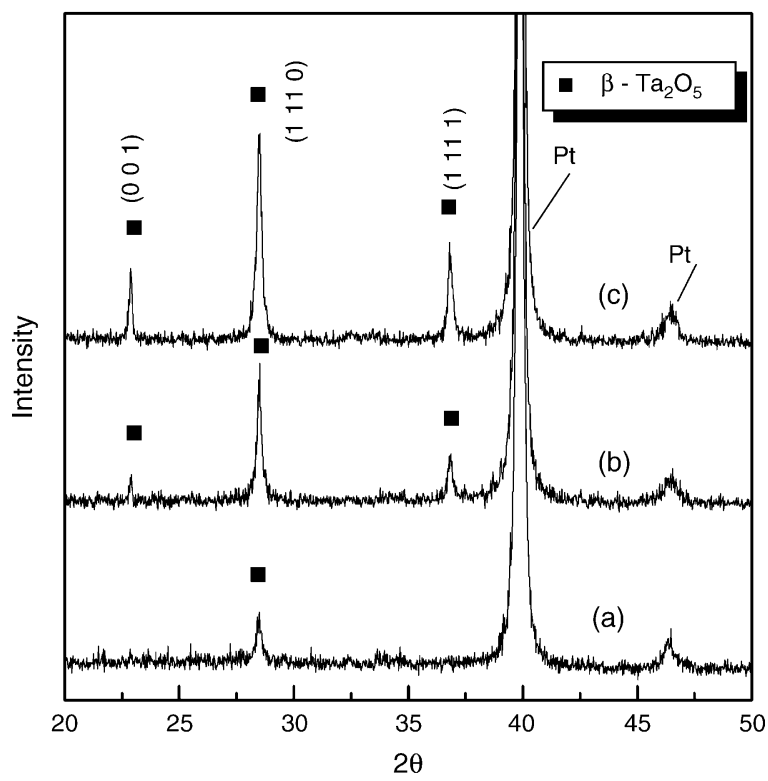

Fig. 6. X-ray diffraction analysis for $\mathrm{Ta}_{2} \mathrm{O}_{5}$ thin films crystallized via $\mathrm{HPC}$ process at $350^{\circ} \mathrm{C}$ for (a) $15 \mathrm{~min}$, (b) $30 \mathrm{~min}$, and (c) $60 \mathrm{~min}$.

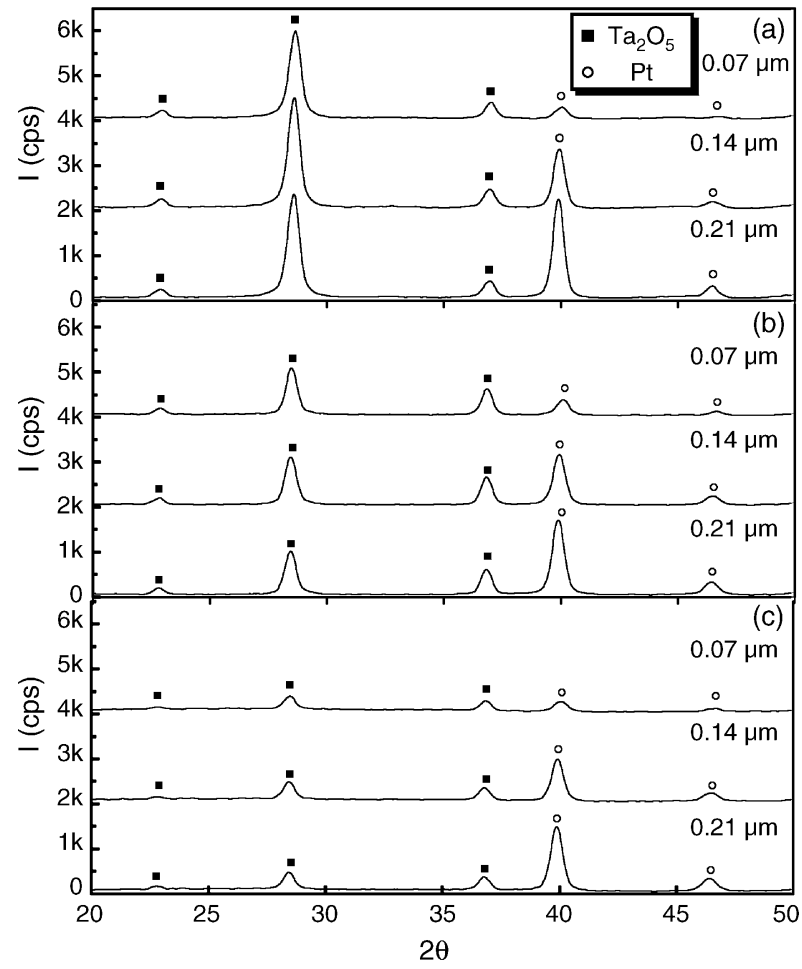

Fig. 7. GIXRD diffraction patterns of $\mathrm{Ta}_{2} \mathrm{O}_{5}$ thin films annealed at (a) $700{ }^{\circ} \mathrm{C}$ under atmospheric pressure, (b) $350^{\circ} \mathrm{C}$ under $16.5 \mathrm{MPa}$, and (c) $320^{\circ} \mathrm{C}$ under $11.3 \mathrm{MPa}$.

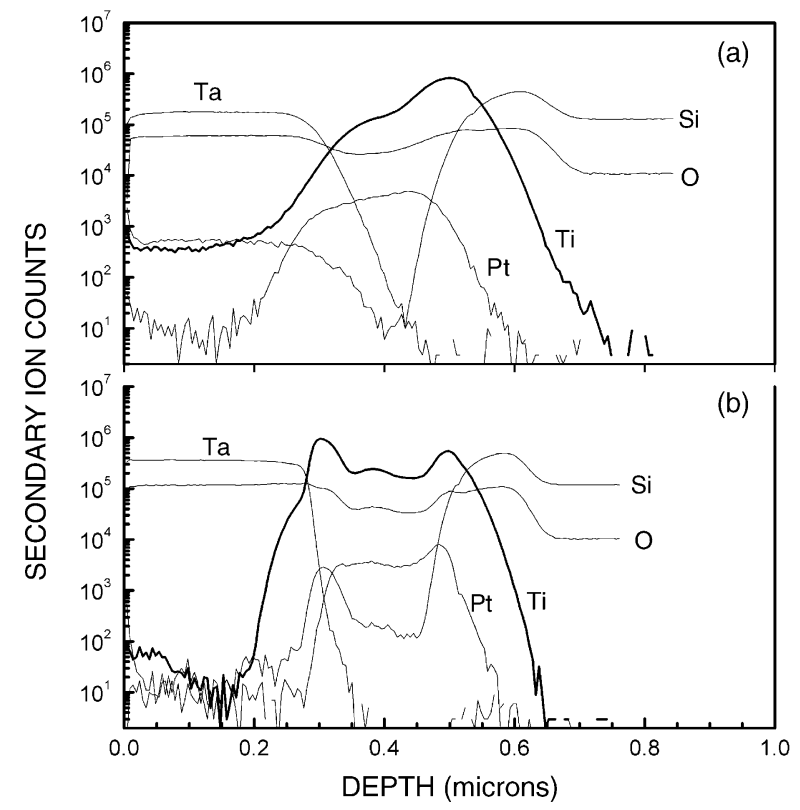

Fig. 8. Secondary ion mass spectroscopic profiles of $\mathrm{Ta}_{2} \mathrm{O}_{5}$ thin films on $\mathrm{Pt} / \mathrm{Ti} / \mathrm{SiO}_{2} / \mathrm{Si}$ substrates. The films were annealed at (a) $700^{\circ} \mathrm{C}$ under atmospheric pressure and (b) $350^{\circ} \mathrm{C}$ under $16.5 \mathrm{MPa}$.

\section{Conclusions}

The crystallization process of $\mathrm{Ta}_{2} \mathrm{O}_{5}$ thin films deposited via a metal-organic decomposition process was investigated 
in this study. When $\mathrm{Ta}_{2} \mathrm{O}_{5}$ films were annealed under atmospheric pressure, the crystallization of the films started to take place at $700{ }^{\circ} \mathrm{C}$. As the HPC process was adopted and annealing at $16.5 \mathrm{MPa}$ was performed, the crystallization temperature of $\mathrm{Ta}_{2} \mathrm{O}_{5}$ films was substantially lowered to $350^{\circ} \mathrm{C}$. The development of crystallized $\mathrm{Ta}_{2} \mathrm{O}_{5}$ during the HPC process was related to the applied pressure and heating durations. According to SIMS analysis, crystallized $\mathrm{Ta}_{2} \mathrm{O}_{5}$ phase was found to homogeneously distribute within the films prepared via the HPC process. During high-temperature annealing under atmospheric pressure, the silicon species diffused from the substrates into $\mathrm{Ta}_{2} \mathrm{O}_{5}$ layers, and the dielectric constants of the prepared films were decreased. On the other hand, the interdiffusion between the substrates and dielectric layers was suppressed during the HPC process by lowering the heating temperatures, and the dielectric constants of $\mathrm{Ta}_{2} \mathrm{O}_{5}$ thin films were increased. The HPC process was confirmed to not only effectively reduce the thermal budget and energy consumption during film processing, but also improve the dielectric properties of $\mathrm{Ta}_{2} \mathrm{O}_{5}$ thin films.

\section{References}

1. Hitchens, W. R., Krusell, W. C. and Dobkin, D. M., Tantalum oxide thin films for dielectric applications by low pressure chemical vapor deposition physical and electrical properties. J. Electrochem. Soc., 1993, 140, 2615-2621.

2. Kaga, T., Ohkura, M., Murai, F., Yokoyama, N. and Takeda, E., Process and device technologies for $1 \mathrm{Gbit}$ dynamic random-access memory cells. J. Vac. Sci. Technol., 1995, B13, 2329-2334.

3. Hasimoto, C., Oikawa, H. and Honma, N., Leakage-current reduction in thin $\mathrm{Ta}_{2} \mathrm{O}_{5}$ films for high-density VLSI memories. IEEE Trans. Electron Devices, 1989, ED-36, 14-18.

4. Choi, G. M., Tuller, H. L. and Haggerty, J. S., Alpha-Ta $2 \mathrm{O}_{5}$ : an intrinsic fast oxygen ion conductor. J. Electrochem. Soc., 1989, 136, 835-838.

5. Hensler, D. H., Cuthbert, J. D., Martin, R. J. and Tien, P. K., Optical propagation in sheet and pattern generated films of $\mathrm{Ta}_{2} \mathrm{O}_{5}$. Appl. Opt., 1971, 10, 1037-1042.

6. Terui, H. and Kobayashi, M., Refractive-index-adjustable $\mathrm{SiO}_{2}-\mathrm{Ta}_{2} \mathrm{O}_{5}$ films for integrated optical circuits. Appl. Phys. Lett., 1978, 32, 666-668.
7. Oehrlein, G. S., Oxidation temperature dependence of the dc electrical conduction characteristics and dielectric strength of thin $\mathrm{Ta}_{2} \mathrm{O}_{5}$ films on silicon. J. Appl. Phys., 1986, 59, 1587-1595.

8. Oehrlein, G. S. and Reisman, A., Electrical properties of amorphous tantalum pentoxide thin films on silicon. J. Appl. Phys., 1983, 54, 6502-6508.

9. Oehrlein, G. S., d'Heurle, F. M. and Reisman, A., Some properties of crystallized tantalum pentoxide thin films on silicon. J. Appl. Phys., 1984, 55, 3715-3725.

10. Atanassova, E., Novkovski, N., Paskaleva, A. and PecovskaGjorgjevich, M., Oxygen annealing modification of conduction mechanism in thin rf sputtered $\mathrm{Ta}_{2} \mathrm{O}_{5}$ on Si. Solid State Electron., 2002, 46, 1887-1898.

11. Ohishi, T., Maekawa, S. and Katoh, A., Synthesis and properties of tantalum oxide films prepared by the sol-gel method using photo irradiation. J. Non-Cryst. Solids, 1992, 147-148, 493-498.

12. Kishiro, K., Inoue, N., Chen, S. C. and Yoshimaru, M., Structure and electrical properties of thin $\mathrm{Ta}_{2} \mathrm{O}_{5}$ deposited on metal electrodes. Jpn. J. Appl. Phys., 1998, 37, 1336-1339.

13. Lu, C. H., U.S. Patent No. 6143366 (2000).

14. Lu, C. H., Hwang, W. J. and Sun, Y. C., Ferroelectric lead zirconate titanate thin films synthesized via a high-pressure crystallization process. Jpn. J. Appl. Phys., 2002, 41, 6674-6678.

15. Powder Diffraction File, Card No. 25-922. International Center for Diffraction Data, Newtown Square, PA.

16. Hiratani, M., Kimura, S., Hamada, T., Iijima, S. and Nakanishi, N., Hexagonal polymorph of tantalum-pentoxide with enhanced dielectric constant. Appl. Phys. Lett., 2002, 81, 2433-2435.

17. Lin, J., Susuki, T., Mattsunaga, D. and Hieda, K., Low crystallization temperature for $\mathrm{Ta}_{2} \mathrm{O}_{5}$ thin films. Jpn. J. Appl. Phys., 2003, 42, 7023-7024.

18. Yao, B., Li, F. S., Lin, X. M., Ding, B. Z., Su, W. H. and Hu, Z. Q., Observation of ion-induced alloy phase formation in an immiscible Y-Ta system. J. Non-Cryst. Solids, 1997, 217, 308-316.

19. Liao, S. C., Mayo, W. E. and Pae, K. D., Theory of high pressure/low temperature sintering of bulk nanocrystalline $\mathrm{TiO}_{2}$. Acta Mater., 1997 , 45, 4027-4040.

20. Moon, J., Kerchner, J. A., Krarup, H. and Adair, J. H., Hydrothermal synthesis of ferroelectric perovskites from chemically modified titanium isopropoxide and acetate salts. J. Mater. Res., 1999, 14, 425-435.

21. Huang, T. C., Advances in X-ray Analysis. Plenum Press, New York, 1990, p. 91.

22. Lau, W. S., Qian, P. W., Sandler, N. P., McKinley, K. A. and Chu, P. K., Evidence that $\mathrm{N}_{2} \mathrm{O}$ is a stronger oxidizing agent than $\mathrm{O}_{2}$ for the post-deposition annealing of $\mathrm{Ta}_{2} \mathrm{O}_{5}$ on Si capacitors. Jpn. J. Appl. Phys., 1997, 36, 661-666. 